\title{
Reduced Recovery Times with Total Intravenous Anesthesia in Patients with Obstructive Sleep Apnea
}

\author{
Leonard Estephan \\ Thomas Jefferson University, leonard.estephan@students.jefferson.edu \\ Matthew Stewart \\ Thomas Jefferson University, matthew.stewart@students.jefferson.edu \\ Maurits Boon \\ Thomas Jefferson University, Maurits.Boon@jefferson.edu \\ Colin Huntley \\ Thomas Jefferson University, Colin.Huntley@jefferson.edu
}

Follow this and additional works at: https://jdc.jefferson.edu/si_ctr_2023_phase1

Part of the Sleep Medicine Commons, and the Translational Medical Research Commons

Let us know how access to this document benefits you

\section{Recommended Citation \\ Estephan, Leonard; Stewart, Matthew; Boon, Maurits; and Huntley, Colin, "Reduced Recovery Times with Total Intravenous Anesthesia in Patients with Obstructive Sleep Apnea" (2021).}

Phase 1. Paper 46.

https://jdc.jefferson.edu/si_ctr_2023_phase1/46

This Article is brought to you for free and open access by the Jefferson Digital Commons. The Jefferson Digital Commons is a service of Thomas Jefferson University's Center for Teaching and Learning (CTL). The Commons is a showcase for Jefferson books and journals, peer-reviewed scholarly publications, unique historical collections from the University archives, and teaching tools. The Jefferson Digital Commons allows researchers and interested readers anywhere in the world to learn about and keep up to date with Jefferson scholarship. This article has been accepted for inclusion in Phase 1 by an authorized administrator of the Jefferson Digital Commons. For more information, please contact: JeffersonDigitalCommons@jefferson.edu. 


\title{
Sidney Kimmel
}

Medical College.

at Thomas Jefferson University

\section{Total IV Propofol vs. Sevoflurane Gas Anesthesia in Patients with Obstructive Sleep Apnea}

Leonard Estephan, Matthew Stewart, Adam Thaler DO, Tingting Zhan PhD, Patrick Hunt MD,

Maurits Boon MD, Colin Huntley MD*

\author{
Department of Otolaryngology - Head and Neck Surgery \\ Department of Anesthesiology \\ Department of Pharmacology and Experimental Therapeutics
}


Sidney Kimmel

Medical College.

at Thomas Jefferson University

\section{Disclosures}

- No disclosures to report 


\section{Sidney Kimmel}

Medical College.

\section{Introduction}

at Thomas Jefferson University

- Obstructive sleep apnea (OSA) is a common, yet serious condition ${ }^{1}$

- Repetitive nocturnal airway collapse, leading to cessation of breathing

- Associated with stroke, hypertension, arrhythmias, decreased cognitive function, and diminished quality of life ${ }^{2}$

- Diagnosis of OSA includes either a home or in-laboratory sleep study to establish the extent of airway obstruction

- Study results will typically report an apnea-hypopnea index (AHI), denoting severity of disease

- $\mathrm{AHI}$ - apnea and hypopnea events per hour

- Effective first-line treatments of OSA include continued positive airway pressure (CPAP) therapy or mandibular repositioning ${ }^{3}$
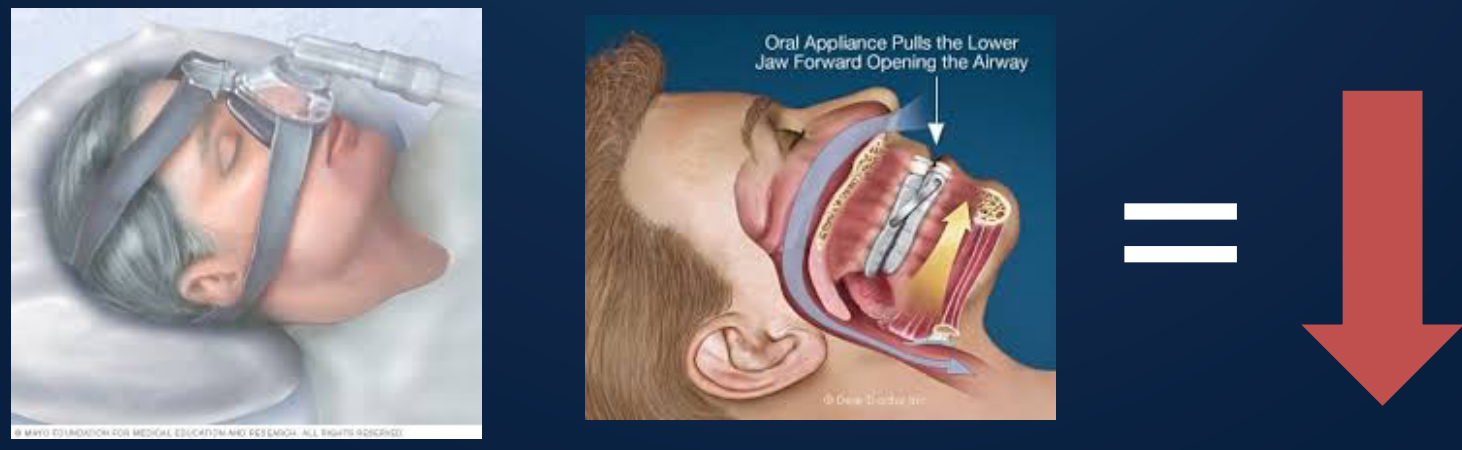

Compliance! 


\section{Sidney Kimmel}

Medical College.

at Thomas Jefferson University

\section{Introduction}

- Following failure of CPAP or mandibular device, several surgical manipulations for OSA treatment exist

- Procedures selected depend on location of obstruction and individual patient anatomy ${ }^{4}$

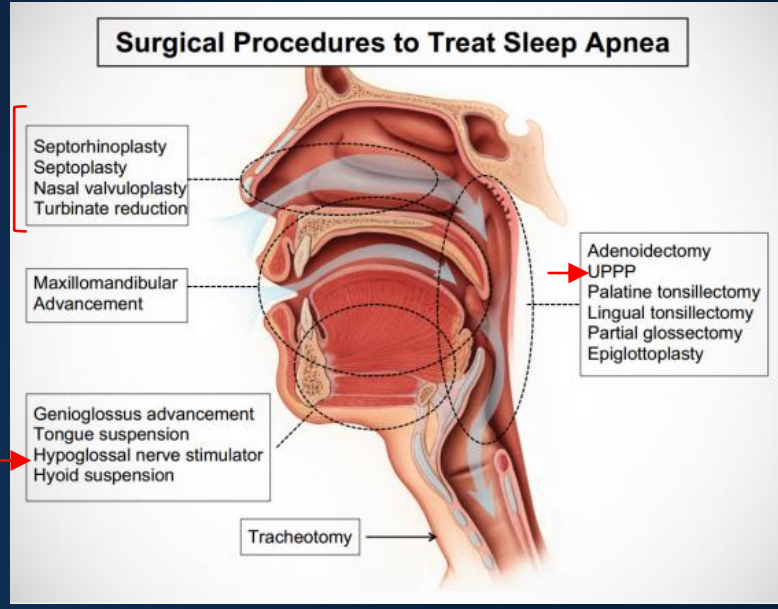

- Currently, a standard of care does not exist for the anesthetic approach utilized for OSA patients receiving surgery

- Two highly utilized general anesthetic agents were evaluated in this study: Total Intravenous Anesthesia (TIVA) and Sevoflurane Gas (SEVO)

- Conflicting literature exists as to which method is superior

- Meta-analyses have shown that TIVA leads to faster recovery times with less postoperative nausea ${ }^{5}$

- Potential impacts on efficiency and cost of recovery care, and patient satisfaction 


\section{Objectives \& Hypothesis}

- Research Question: How does Total Intravenous Anesthesia (TIVA) compare with Sevoflurane Gas (SEVO) with respect to resultant postoperative experience and recovery time in OSA patients undergoing surgery?
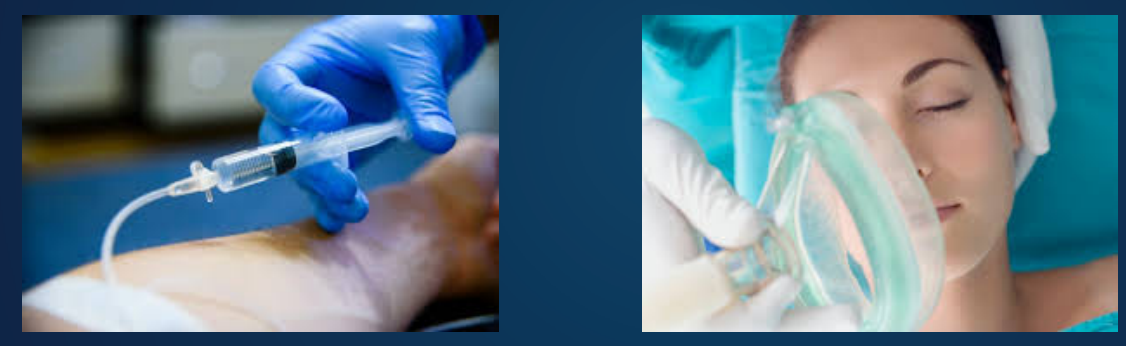

- Hypothesis: OSA patients undergoing surgery will experience reduced postoperative nausea and faster recovery times following administration of TIVA compared with patients that receive SEVO. 


\section{Approach \& Results}

- Study design: Retrospective Cohort Study

- Population: OSA patients undergoing corrective surgery (Jan. 2019-Dec 2019)

- Surgeries included nasal surgeries, uvulopalatopharyngoplasty (UPPP) and upper airway stimulation (UAS)

- SEVO $(n=86)$

- $\quad$ Nasal $(n=47)$

- $\operatorname{UAS}(n=29)$

- $\operatorname{UPPP}(n=10)$

- TIVA $(n=62)$

- Nasal $(n=24)$

- $\operatorname{UAS}(n=30)$

- $\operatorname{UPPP}(n=8)$

- Intervention: Administration of TIVA with propofol + remifentanil

- Comparison: Outcomes of patients receiving SEVO

- All data was obtained from Epic medical history charts

- Outcomes collected included time-based measures (total surgery and anesthesia time, time to emergence, time to PACU phase I/II completion, and total recovery time), incidence of postoperative nausea

- Rationale behind this approach:

- Retrospective review of patients with known anesthesia modality

- Appropriate time data was available to conclude if recovery times differed

- Adverse events and complications occurring weeks later were also obtainable with this approach

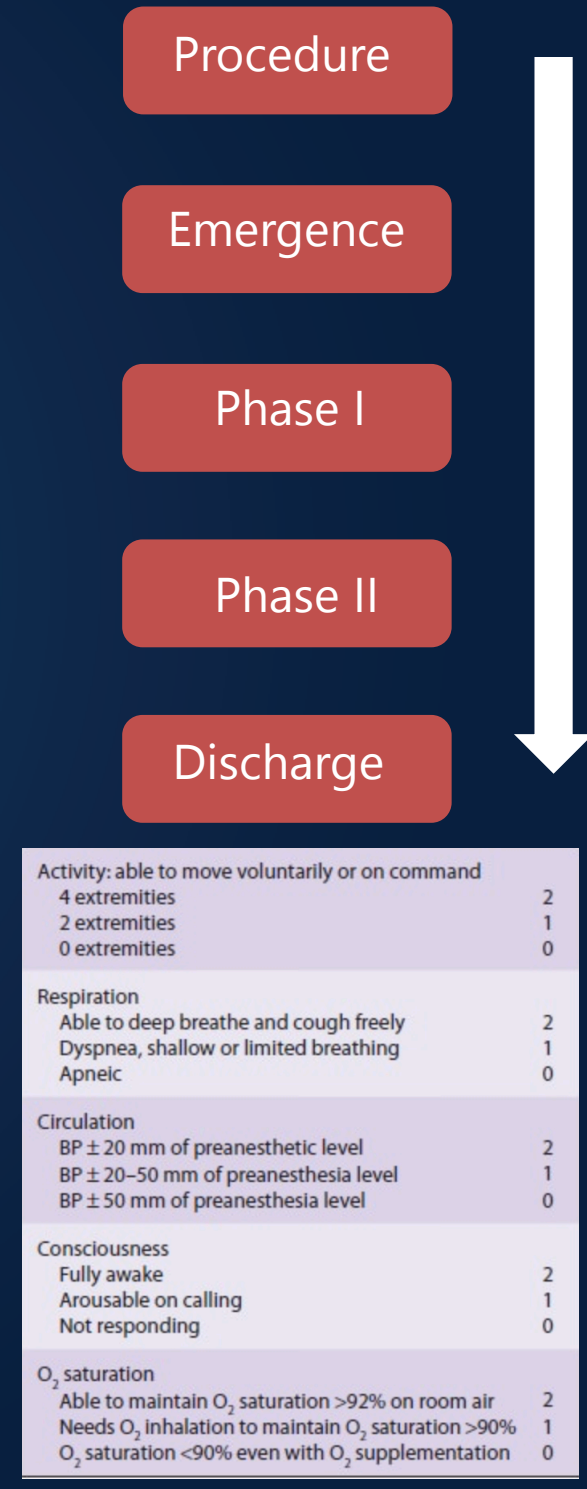




\section{Approach \& Results}

- Methods of analysis:

- Analyses were performed using Graphpad Prism software using the following tests:

- Unpaired nonparametric Mann-Whitney $U$ tests (time comparisons/demographics)

- Fischer's Exact tests (categorical data)

- Multiple linear regression (correlating OSA severity with recovery time) 
Sidney Kimmel Medical College. at Thomas Jefferson University

\section{Approach \& Results}

\begin{tabular}{|c|c|c|c|}
\hline Demographics & $\begin{array}{l}\text { SEVO Patients } \\
(n=86)\end{array}$ & $\begin{array}{l}\text { TIVA Patients } \\
(n=62)\end{array}$ & P Value \\
\hline Age & $52.7 \pm 11.2$ years & $55.4 \pm 12.1$ years & $P=.1265$ \\
\hline Sex & $\begin{array}{l}78 \% \text { Males }(n=67) \\
22 \% \text { Females }(n=19)\end{array}$ & $\begin{array}{l}77 \% \text { Males }(n=48) \\
23 \% \text { Females }(n=14)\end{array}$ & $P=1.00$ \\
\hline Race & $\begin{array}{l}78 \% \text { Caucasian }(n=67) \\
14 \% \text { African American ( } n=12) \\
5 \% \text { Hispanic }(n=3) \\
6 \% \text { Other }(n=4)\end{array}$ & $\begin{array}{l}91 \% \text { Caucasian }(n=56) \\
3 \% \text { African American }(n=2) \\
6 \% \text { Hispanic }(n=4) \\
0 \% \text { Other }(n=0)\end{array}$ & $\begin{array}{l}P=.0737 \\
P=.0433 \\
P=.4530 \\
P=.1426\end{array}$ \\
\hline BMI & $31.1 \pm 4.7 \mathrm{~kg} / \mathrm{m}^{2}$ & $29.8 \pm 3.6 \mathrm{~kg} / \mathrm{m}^{2}$ & $P=.1424$ \\
\hline $\mathrm{AHI}$ & $31.6 \pm 24.9$ & $30.5 \pm 18.9$ & $P=.8848$ \\
\hline $\begin{array}{l}\text { OSA Severity } \\
\% \text { Mild OSA } \\
\text { AHI } \geq 5-<15 \\
\% \text { Moderate OSA } \\
\text { AHI } \geq 15-<30 \\
\% \text { Severe OSA } \\
\text { AHI } \geq 30\end{array}$ & $\begin{array}{l}24 \% \text { Mild OSA }(n=21) \\
34 \% \text { Moderate OSA }(n=29) \\
42 \% \text { Severe OSA }(n=36)\end{array}$ & $\begin{array}{l}\text { 19\% Mild OSA }(n=12) \\
37 \% \text { Moderate OSA }(n=23) \\
44 \% \text { Severe OSA }(n=27)\end{array}$ & $\begin{array}{l}P=.0774 \\
P=.1247 \\
P=.3585\end{array}$ \\
\hline $\begin{array}{l}\text { Surgical Procedure } \\
\% \text { Nasal Surgery } \\
\% \text { Upper Airway Stimulation (UAS) } \\
\% \text { Uvulopalatopharyngoplasty (UPPP) }\end{array}$ & $\begin{array}{l}55 \% \text { Nasal }(n=47) \\
34 \% \text { UAS }(n=29) \\
12 \% \text { UPPP }(n=10)\end{array}$ & $\begin{array}{l}39 \% \text { Nasal }(n=24) \\
48 \% \text { UAS }(n=30) \\
13 \% \text { UPPP }(n=8)\end{array}$ & $\begin{array}{l}P=.0672 \\
P=.0893 \\
P=.8051\end{array}$ \\
\hline
\end{tabular}


Sidney Kimmel Medical College. at Thomas Jefferson University

\section{Approach and Results}

Median PACU phase I time decreased with TIVA across all surgical subtypes. Total recovery decreased in all surgeries except UPPP.

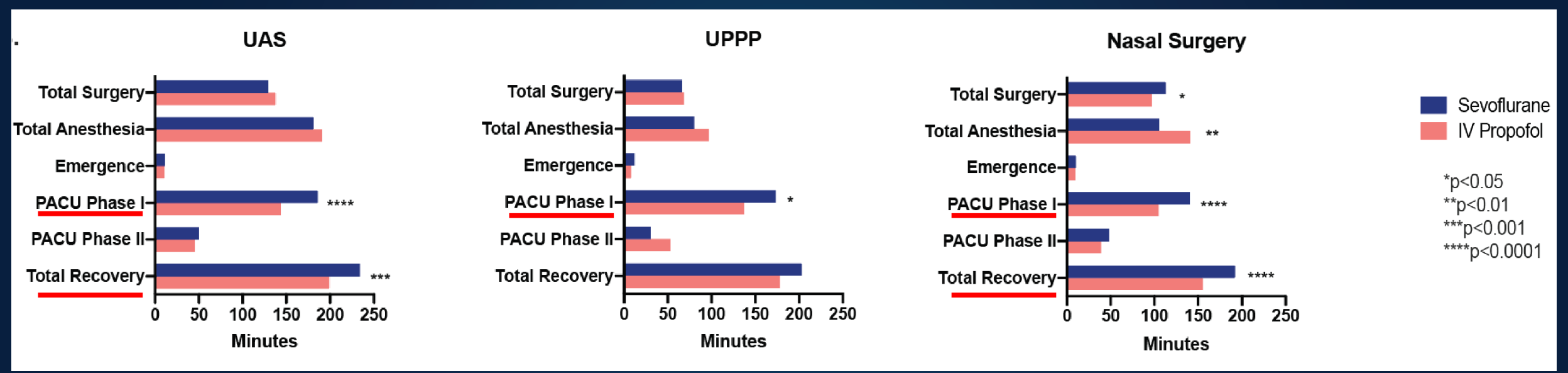

UAS Median PACU phase I difference: $42.5 \mathrm{~min}(\mathrm{p}<.001,95 \% \mathrm{Cl} 20.00-61.00)$ UPPP Median PACU phase I difference: $36 \mathrm{~min}(p=.022,95 \% \mathrm{Cl} 6.00-83.00)$ Nasal Median PACU phase I difference: 35.5 min ( $p<.001,95 \% \mathrm{Cl} 18.00$ - 52.00) 
Sidney Kimmel

Medical College.

at Thomas Jefferson University

\section{Approach and Results}

Median PACU phase I time decreased with TIVA across all severities of OSA with surgeries combined.

Mild OSA

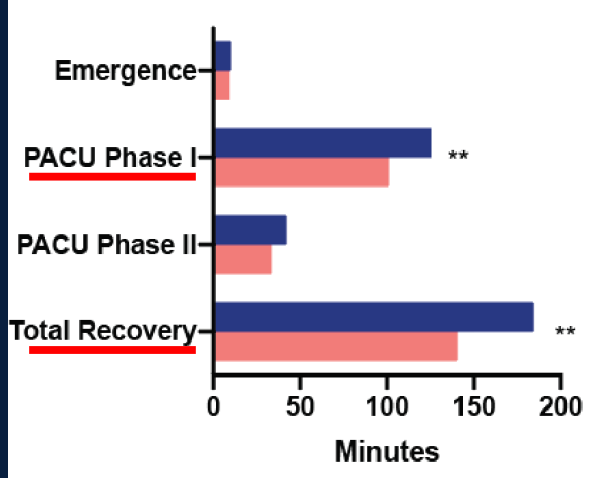

Moderate OSA

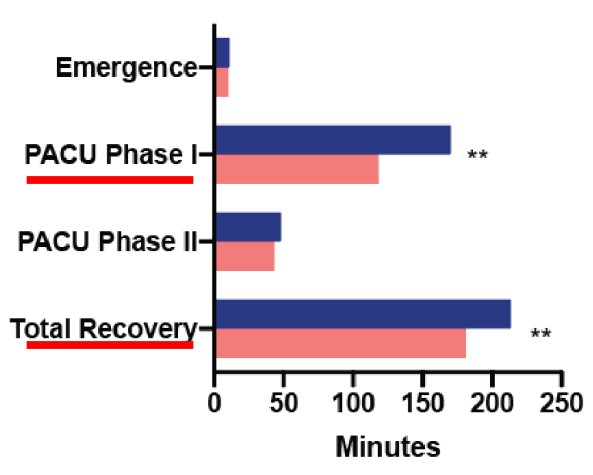

Severe OSA

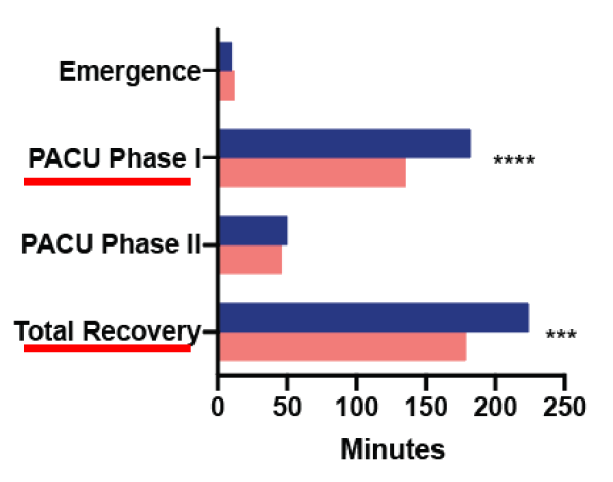

Sevoflurane

IV Propofol

${ }^{*} p<0.05$

$* \star *<0.01$

$* * * 00.001$

$* * * * 0<0.0001$

Mild Median PACU phase I difference: $23.5 \mathrm{~min}$ ( $p=.004,95 \%$ CI 11.00 - 55.00)

Moderate PACU phase I difference: $52 \min (p=.004,95 \%$ CI $11.00-63.00)$

Severe Median PACU phase I difference: $47 \mathrm{~min}(p<.001,95 \% 16.00-56.00)$ 
Sidney Kimmel Medical College. at Thomas Jefferson University

\section{Approach and Results}

Logarithmic 2-fold AHI increases correlates with increased PACU phase I time in SEVO patients.

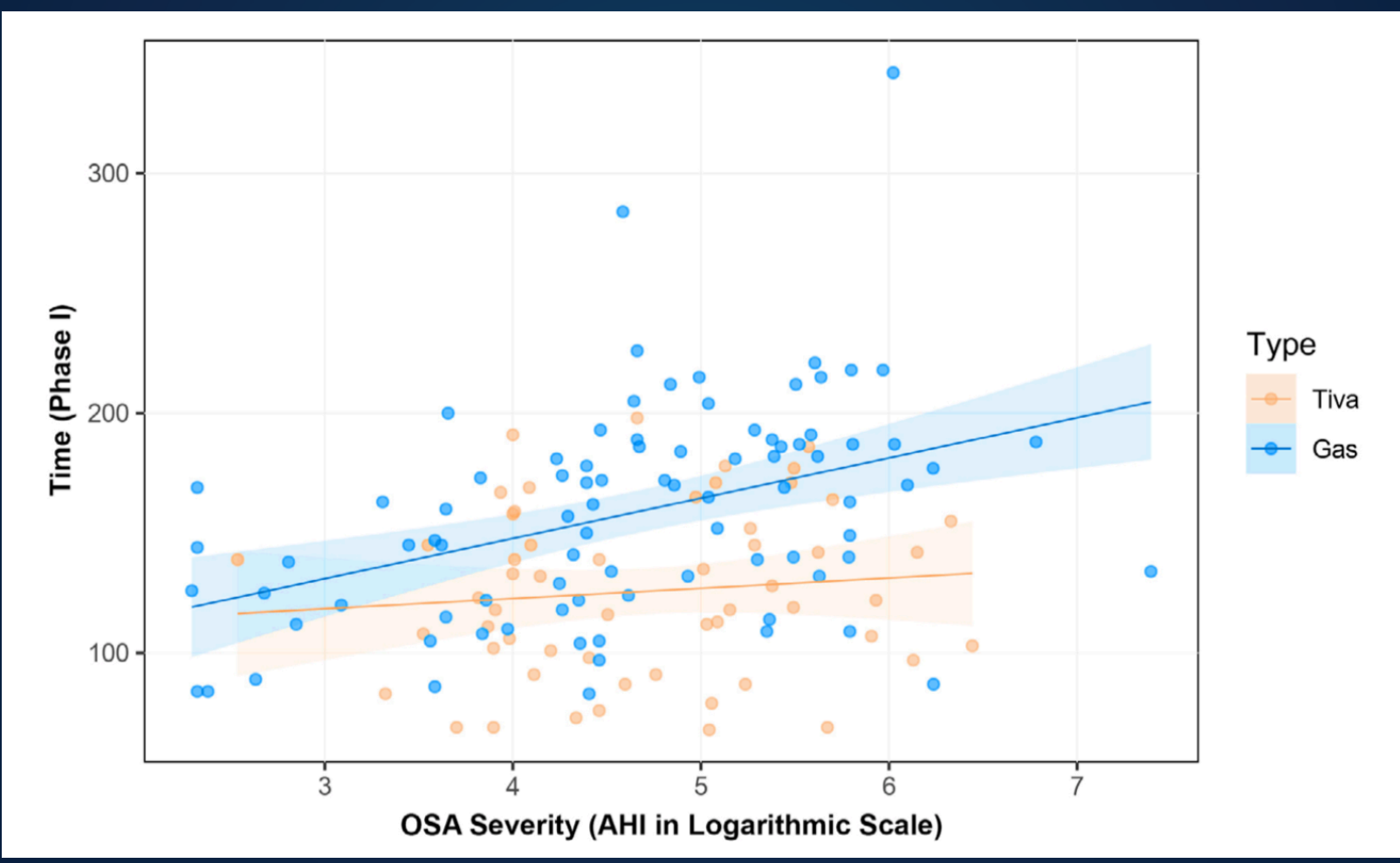

SEVO phase I time increase: $16.8 \mathrm{~min}(\mathrm{p}<.001,95 \% \mathrm{CI} 9.2$ to 22.4$)$ TIVA phase I time increase: $4.3 \mathrm{~min}(\mathrm{p}=.489,95 \% \mathrm{CI}-7.9$ to 16.5$)$ 


\section{Approach and Results}

Incidence of postoperative nausea and vomiting (PONV) did not differ in cohorts based on anesthesia received.

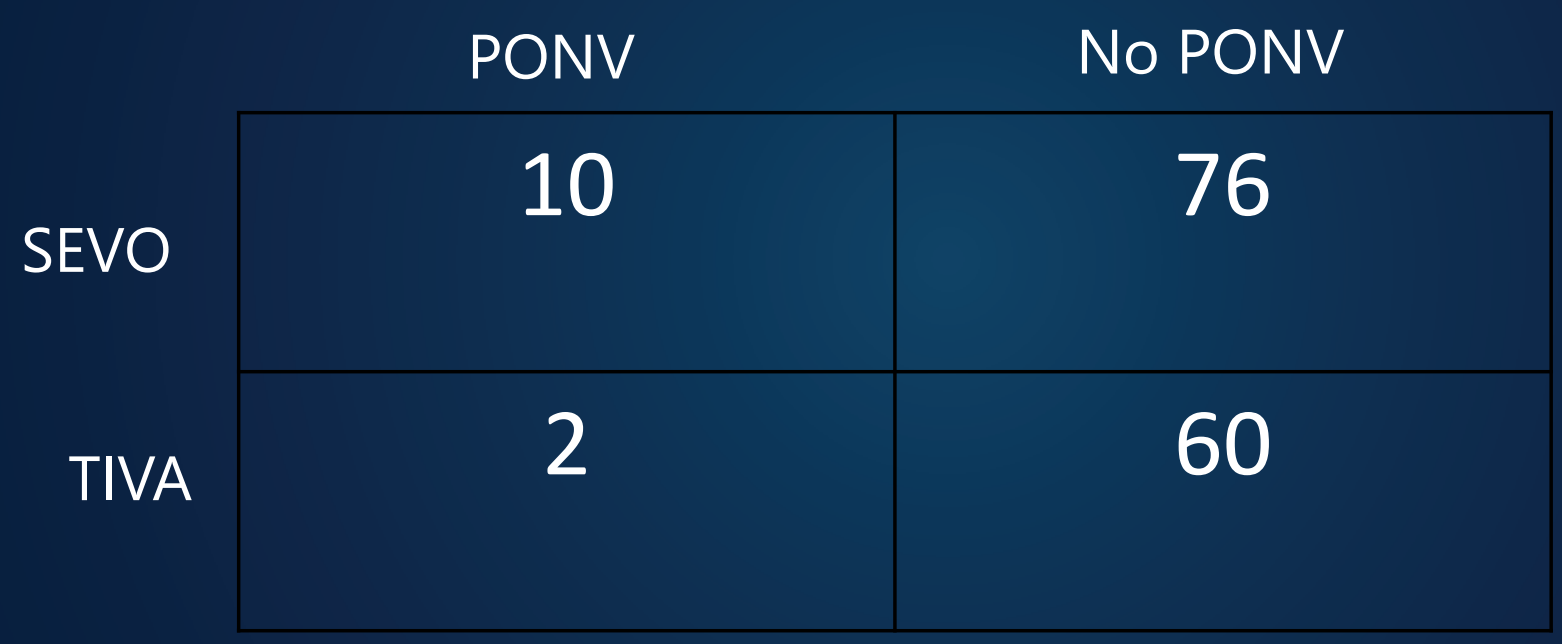

Fischer's Exact Test of PONV Incidence: $p=.07$ 


\section{Conclusions}

- Based on this retrospective cohort:

- Surgical OSA patients experience reduced recovery time with TIVA regardless of OSA severity or surgery received

- OSA patients receiving SEVO experience increased time spent in recovery with increasing OSA severity

- Incidence of PONV did not differ based on anesthesia received, but may do so with an increased sample size

- Overall, our findings of reduced recovery time after TIVA are consistent with meta-analyses of the general population $^{5}$

- Implications of these findings may include improved efficiency of care delivery and patient satisfaction, and potentially reduced cost of recovery care

- Further studies are needed to confirm these impacts 


\section{Future Directions}

- Extensions of this study include:

- Prospective RCT placing patients in either a TIVA or SEVO group

- More thorough assessment of postoperative pain and nausea

- Cost analysis of this cohort utilizing Jefferson financial data and billing to insurance

- Assessment of TIVA vs. SEVO in non-OSA patients undergoing otolaryngologic procedures (tonsillectomy, rhinoplasty, facelift, etc.) 


\section{Acknowledgements}

- Thank you to all the faculty in the Departments of Otolaryngology, Anesthesia, and Pharmacology and Experimental Therapeutics for their contributions to this study. 
- 1. Punjabi NM. The epidemiology of adult obstructive sleep apnea. Proceedings of the American Thoracic Society. 2008; 5: 136-43.

- 2. Krieger J, McNicholas WT, Levy P, et al. Public health and medicolegal implications of sleep apnoea. The European respiratory journal. 2002; 20: 1594-609.

- 3. Lorenzi-Filho G, Almeida FR and Strollo PJ. Treating OSA: Current and emerging therapies beyond CPAP. Respirology (Carlton, Vic). 2017; 22: 1500-7.

- 4. . Carvalho B, Hsia J and Capasso R. Surgical therapy of obstructive sleep apnea: a review. Neurotherapeutics : the journal of the American Society for Experimental NeuroTherapeutics. 2012; 9: 7106.

- 5. Gupta A, Stierer T, Zuckerman R, Sakima N, Parker SD, Fleisher LA. Comparison of recovery profile after ambulatory anesthesia with propofol, isoflurane, sevoflurane and desflurane: a systematic review. Anesth Analg. 2004;98(3):. 